\title{
ADSORPTION ISOTHERM STUDIES ON METHYLENE BLUE DYE REMOVAL USING NATURALLY AVAILABLE BIOSORBENT
}

\author{
Narayana Saibaba KV and Ravi Vital Kandisa* \\ Department of Biotechnology, GITAM Institute of Technology, GITAM (Deemed to be \\ University), Gandhi Nagar, Rushikonda, Visakhapatnam, Andhra Pradesh-530045 \\ *E-mail: vittubiotech@gmail.com
}

\begin{abstract}
Textile industry is one of the fast growing industries and is consuming and polluting large volumes of water. Four isotherms i.e. Langmuir, Freundlich, Tempkin and Dubinin-Radushkevich were studied to evaluate the adsorbent efficiency of Vigna Trilobata pod in removal of dye from aqueous solution. Methylene blue was taken as the model pollutant in this study. Among all the above mentioned isotherms Freundlich adsorption isotherm model was found to be fitted well with the experimental data with high regression coefficient, $R^{2} \geq 99$. Isotherm studies proved that Vigna Trilobata pod is very efficient for the removal of Methylene blue.
\end{abstract}

Keywords: Waste water treatment, Biosorption, Isotherm Studies, Dye Pollution, Industrial pollution

(C) RASĀYAN. All rights reserved

\section{INTRODUCTION}

Dyes are extensively used in textile, paint, printing, leather and tanning industries. The textile industrial sector is considered to be one of the fast-growing industrial sectors. This growth may have a grave impact on the environment ${ }^{1}$ since it consumes considerably high purity water and generates equally large volumes of highly colored polluted water. Every year large amounts, 5000 tons, of dyes are reaching the water sources. ${ }^{2}$ Industries are required to control their discharge by using some measures for environmental protection.,

Generally, the effluents from textile industries contain various chemicals, primarily dyes, employed for treatments such as scouring, dyeing and finishing of textiles. Lubricants used in waving equipment, spinning equipment and knitting and other equipment also reach these effluents along with additive chemicals. Textile industry effluents also contain non-fibrous contaminants removed during initial stages of the textile manufacturing process, antistatic agents received through synthetic fibers. ${ }^{5}$ Toxic dyes that reach into the water bodies through textile industries, not only polluting water but also the whole ecosystem and making us prone to chemical exposure and its related health hazards.

Methods such as Ion exchange, Membrane separation processes, Sedimentation, Precipitation, Flotation, Adsorption and oxidation and Biodegradation are generally used for the treatment of aqueous solutions. ${ }^{6}$ Among them, adsorption is the widely used treatment method for textile effluents. In spite of the frequent utilization of activated carbon as an adsorbent in wastewater treatment frame works, commercially available activated carbon remains a costly material. The safe, cheap and comfortable strategies are required for the treatment of dye house effluents which stimulated researchers to focus on the preparation of biosorbents from easily available and least expensive sources. ${ }^{7}$ Therefore, a non-conventional method such as biosorption seems to be a good method in the future; thus utilization of natural biodegradable bio sorbents with minimal effort is the new choice for the environmentalists. ${ }^{23}$ These biosorbents are ecofriendly; commercially inexpensive, easily available furthermore ensure complete safety. ${ }^{7}$

Rasayan J. Chem., 12(4), 2176-2182(2019)

http://dx.doi.org/10.31788/RJC.2019.1245478

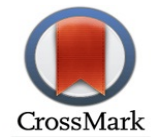


RASĀYAN J. Chem.

Vol. 12 | No. 4 |2176 - 2182| October - December | 2019

\section{EXPERIMENTAL}

\section{Raw Materials}

Chemicals used in this experiment are procured from coastal enterprises, Visakhapatnam, India. Glassware and biosorbent were washed under running tap water followed by deionised water.

\section{Preparation of Biosorbent}

Vigna Trilobata pod collected from natural sources was washed thoroughly under the running tap water, followed by deionised water. This procedure was continued until the adsorbent did not contain any particles or no color appeared in the wash water. Then adsorbent material was dried at sun light for 48 hours, grounded and subjected to sieving to collect different sized particles.

\section{Preparation of Dye Solutions}

Methylene blue is a synthetic dye generally utilized in cotton and wool industries. Chemically it is heterocyclic aromatic tetra methyl thionine chloride which is cationic in nature. $1.0 \mathrm{~g}$ of Methylene blue was added to $1 \mathrm{~L}$ of distilled water to prepare the stock solution of Methylene blue and it was diluted to prepare the test solutions of various required concentrations $(25 \mathrm{ppm}-150 \mathrm{ppm})$.

\section{Experimental Procedure for Equilibrium Studies}

Various concentrations of $50 \mathrm{ml}$ dye solutions were placed in $250 \mathrm{ml}$ conical flasks, $\mathrm{pH}$ was adjusted by using $0.1 \mathrm{~N} \mathrm{NaOH}$ or $0.1 \mathrm{~N} \mathrm{HCl}$, then $0.1 \mathrm{~g}$ of Vigna Trilobata pod was added to all the Erlenmeyer flasks. All the flasks were placed at $303 \mathrm{~K}$ temperature and at a speed of $150 \mathrm{rpm}$ in an orbital shaker for 90 minutes, after completion of 90 minutes all the flasks were removed from the orbital shaker. Samples were centrifuged for 15 minutes at $3000 \mathrm{rpm}$ and supernatant dye solutions were separated. All the supernatant dye solutions concentrations were determined using UV Spectrophotometer. This procedure was repeated at different temperatures from $303 \mathrm{~K}$, to $323 \mathrm{~K}$ at an interval of $10 \mathrm{~K}$.

\section{Adsorption Isotherm Studies}

In the process of adsorption, adsorbate gets adsorbed on to the adsorbent surface. During the adsorption process adsorbate binds to be solid surface as a film. Type of Adsorption process is usually studied through adsorption isotherm models ${ }^{18}$. Studying adsorption isotherms is very important for the optimization of process conditions during the adsorption process. Correlation between equilibrium solute concentration and adsorption capacity of the adsorbent is expressed in the form of graphical representation. In the present study widely used adsorption models such as Langmuir adsorption isotherm, Freundlich adsorption isotherm, Tempkin adsorption isotherm and Dubinin-Radushkevich adsorption isotherm were studied ${ }^{8,22}$.

\section{Langmuir Isotherm:}

In 1916, Irving Langmuir proposed an adsorption model that explains the variation of adsorption capacity with pressure. This model is proposed by considering the uniform adsorptive surface of the adsorbent and adsorption with equal energies ${ }^{26}$. Langmuir isotherm describes the active surface area with a number of adsorption sites ${ }^{9}$. Non-linear form of Langmuir isotherm model is defined non-linearly as:

Where,

$$
q_{e}=\frac{q_{m} K_{L} C_{e}}{1+K_{L} C_{e}}
$$

$\mathrm{C}_{\mathrm{e}}$ is the equilibrium concentration of the dye solution

$\mathrm{q}_{\mathrm{e}}$ is the equilibrium adsorption capacity ${ }^{10,11}$

$\mathrm{q}_{\mathrm{m}}$ is the maximum equilibrium adsorption capacity

$\mathrm{K}_{\mathrm{L}}$ is the energy of adsorption

The linear form of Langmuir isotherm equation is: ${ }^{24}$

$$
\frac{C_{e}}{q_{e}}=\frac{1}{q_{m} K_{L}}+\frac{C_{e}}{q_{m}}
$$


RASĀYAN J. Chem.

Vol. 12 | No. 4 |2176 - 2182| October - December | 2019

\section{Freundlich Isotherm}

German scientist Freundlich provided an empirical relationship in the year 1909, representing the variation of adsorption capacity of adsorbent with equilibrium concentration in solution which is accurately described much adsorption data ${ }^{12}$. It is the most important multisite adsorption isotherm for rough surfaces ${ }^{13,27}$. Freundlich isotherm model is defined non-linearly as:

$\mathrm{q}_{\mathrm{e}}=\mathrm{K}_{\mathrm{f}} \mathrm{C}_{\mathrm{e}}{ }^{1 / \mathrm{n}}$

Freundlich model is linearly given as:

Where

$$
\ln q_{e}=\ln K_{f}+\frac{1}{n} \ln C_{e}
$$

$\mathrm{K}_{\mathrm{f}}$ is Freundlich constant related to sorption capacity

$1 / \mathrm{n}$ is the Freundlich constant related to the intensity of adsorption

$\mathrm{Ce}$ is the dye concentration at equilibrium state ${ }^{13}$.

\section{Tempkin Isotherm:}

Tempkin isotherm describes the interaction between Vigna Trilobata Pod and dye pollutants. Tempkin considered that the heat of adsorption during the adsorption process decreases linearly ${ }^{11,14,15}$. Tempkin isotherm model can be expressed by the following equation.

$$
\begin{gathered}
q_{e}=\frac{R T}{b} \ln \left(A_{\tau} C_{e}\right) \\
q_{e}=\frac{R T}{b_{\tau}} \ln A_{\tau}+\left(\frac{R T}{b_{\tau}}\right) \ln C_{e} \\
B=\frac{R T}{b_{\tau}} \\
q_{e}=B \ln A_{\tau}+B \ln C_{e}
\end{gathered}
$$

Where

$\mathrm{A}_{\tau}=$ Tempkin constant $(\mathrm{L} / \mathrm{g})$

$\mathrm{b}_{\tau}=$ Tempkin constant which is related to heat of sorption $(\mathrm{J} / \mathrm{mol})$

$\mathrm{C}_{\mathrm{e}}=$ Sorbate equilibrium concentration $(\mathrm{mg} / \mathrm{L})$

$\mathrm{q}_{\mathrm{e}}=$ Adsorption capacity in equilibrium $(\mathrm{mg} / \mathrm{g})$

$\mathrm{R}=$ Universal gas constant $(8.314 \mathrm{~J} / \mathrm{mol} / \mathrm{K})$

$\mathrm{B}=$ Constant related to the heat of sorption $(\mathrm{J} / \mathrm{mol})$

$\mathrm{T}=$ Temperature $(\mathrm{K})^{12,16}$.

\section{Dubinin-Radushkevich (DR) Isotherm}

Dubinin-Radushkevich (DR) adsorption isotherm was also used to describe the adsorption on both homogeneous and heterogeneous surfaces and to distinguish the adsorption of Methylene blue whether it is taking place by physical or chemical adsorption. ${ }^{18,19}$

The linear form of the Dubinin-Radushkevich isotherm model is usually applied by the following equation:

$$
\operatorname{lnq} \mathrm{q}_{\mathrm{e}}=\operatorname{lnq}_{\mathrm{m}}-\beta \varepsilon^{2}
$$

$\varepsilon$ is Polanyi potential can be expressed by the below equation: ${ }^{25}$

$$
\varepsilon=\mathrm{RT} \ln \left(1+\frac{1}{C_{e}}\right)
$$

Where $\mathrm{q}_{\mathrm{e}}$ is the amount of Methylene blue in the Vigna Trilobata Pod $(\mathrm{mg} / \mathrm{g})$ at equilibrium state, $\mathrm{q}_{\mathrm{m}}$ is the maximum adsorption capacity, $\beta$ is the Dubinin-Radushkevich constant, $\mathrm{E}$ is mean free energy $(\mathrm{kJ} / \mathrm{mol}), \mathrm{T}$ is absolute temperature, $\mathrm{R}$ is universal gas constant $(8.314 \mathrm{~J} / \mathrm{mol} \mathrm{K})$ and the intercept of the plot $\operatorname{lnq}_{\mathrm{e}}$ vs $\varepsilon^{2}$ gives maximum adsorption capacity $\mathrm{q}_{\mathrm{m}}$ and slope gives $\beta\left(\mathrm{mol}^{2} / \mathrm{kJ}^{2}\right)^{20}$. 
RASĀYAN J. Chem.

Vol. 12 | No. 4 |2176 - 2182| October - December | 2019

To determine the nature of adsorption for Methylene blue with its mean free energy E per molecule of dye can be computed by the following equation:

$$
E=\frac{1}{\sqrt{2 \beta}}
$$

Where $\beta$ is the isotherm constant and $\mathrm{E}$ is mean adsorption energy ${ }^{15}$

If the value of $\mathrm{E}$ is less than $8 \mathrm{~kJ} / \mathrm{mol}$, it confirms that the adsorption process of dye was controlled by physical sorption and if it is between $8-16 \mathrm{~kJ} / \mathrm{mol}$ it confirms the chemical adsorption ${ }^{21}$.

\section{RESULTS AND DISCUSSION}

A linear plot obtained when the graph was plotted between $C_{e}$ and $C_{e} / q_{e}$ (Fig.-1). It was observed from the values in Table-1, regression coefficient $\mathrm{R}^{2}$ value is 0.99 attained for the Methylene blue dye removal on Vigna Trilobata Pod.

Table-1: Langmuir Isotherm Parameters for the Biosorption of Methylene Blue Dye

\begin{tabular}{c|c|c|c}
\hline Temperature $(\mathrm{K})$ & $\begin{array}{c}\mathrm{K}_{\mathrm{L}} \\
(\mathrm{L} / \mathrm{mg})\end{array}$ & $\begin{array}{c}\mathrm{q}_{\mathrm{m}} \\
(\mathrm{mg} / \mathrm{g})\end{array}$ & $\mathrm{R}^{2}$ \\
\hline 293 & 14.4999 & 71.42 & 0.991 \\
\hline 303 & 16.3983 & 66.66 & 0.979 \\
\hline 313 & 21.5311 & 66.66 & 0.983 \\
\hline 323 & 22.1250 & 62.50 & 0.990 \\
\hline
\end{tabular}

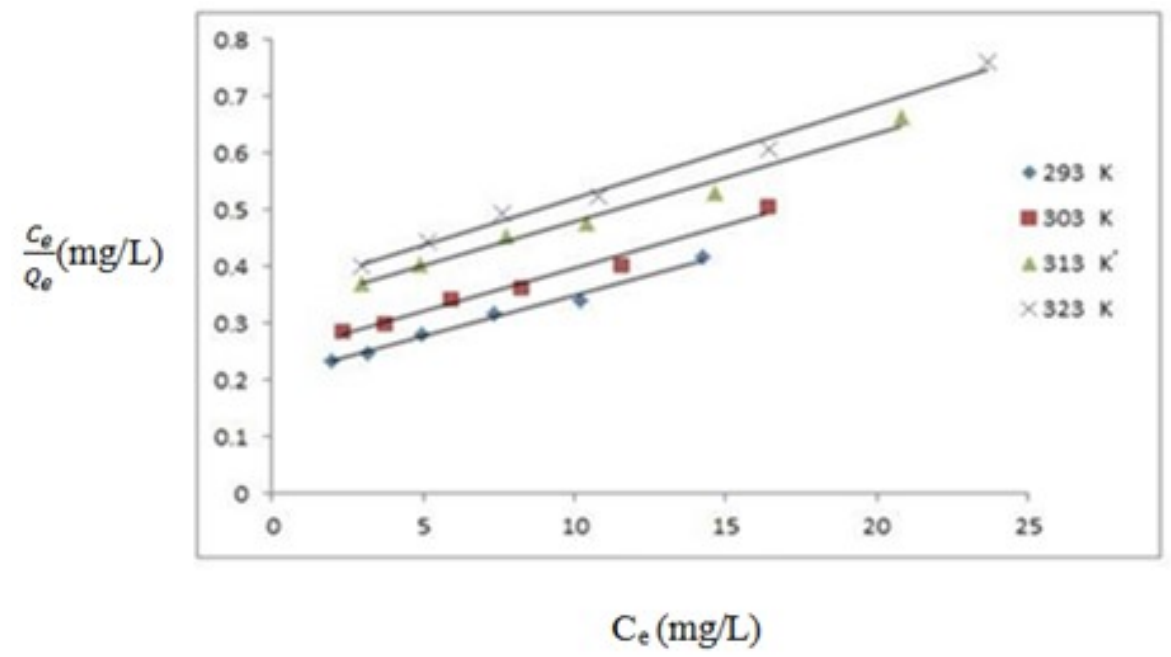

Fig.-1: Langmuir Isotherm for Biosorption of Methylene Blue Dye onto Vigna Trilobata pod

Freundlich parameters $\left(K_{\mathrm{f}}\right.$ and $\left.\mathrm{n}\right)$ calculated from the intercept and slope of the linear plot $\operatorname{lnq}_{\mathrm{e}} \mathrm{vs} \operatorname{lnC}_{\mathrm{e}}$ (Fig.-2) were $5.4695(\mathrm{mg} / \mathrm{g})$ and 1.398 respectively. The application of the linear form of the Freundlich model to Methylene blue was proved by the high regression coefficient $\mathrm{R}^{2}=0.992$. The regression coefficient values are higher than Langmuir's isotherm model. Results showed that removal of Methylene blue on to Vigna Trilobata pod fits well with Freundlich models than the Langmuir's isotherm model which indicates the heterogeneous adsorption (Fig.-2).

The Tempkin isotherm parameters $A_{T}$ and $b_{T}$ were calculated for Methylene blue adsorption onto the Vigna Trilobata pod from the graph between $\operatorname{lnC}_{\mathrm{e}}$ and $\mathrm{q}_{\mathrm{e}}$. Due to the low values of adsorption capacity $\mathrm{A}_{\mathrm{T}}$ and the regression coefficient in compare with other isotherms the data of equilibrium isotherms of Methylene blue adsorption on to Vigna Trilobata pod material is not recommended to describe by the Tempkin model (Fig.-3). 
RASĀYAN J. Chem.

Vol. 12 | No. 4 |2176 - 2182| October - December | 2019

Table-2: Freundlich Adsorption Isotherm Parameters for the Biosorption of Methylene Blue Dye on to Vigna Trilobata Pod

\begin{tabular}{c|c|c|c|c}
\hline Temperature (K) & $1 / \mathrm{n}$ & $\mathrm{n}$ & $\begin{array}{c}\mathrm{K}_{\mathrm{f}} \\
(\mathrm{mg} / \mathrm{g})\end{array}$ & $\mathrm{R}^{2}$ \\
\hline 293 & 0.715 & 1.398 & 5.4695 & 0.992 \\
\hline 303 & 0.725 & 1.379 & 4.637 & 0.986 \\
\hline 313 & 0.721 & 1.386 & 3.812 & 0.989 \\
\hline 323 & 0.707 & 1.414 & 3.595 & 0.990 \\
\hline
\end{tabular}

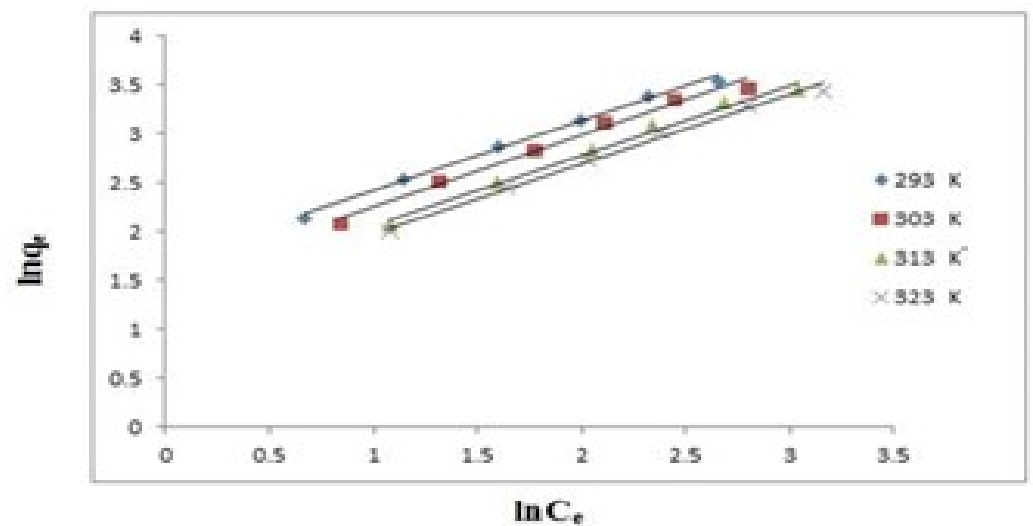

Fig.-2: Freundlich Isotherm for Biosorption of Methylene Blue Dye onto Vigna Trilobata pod

Table-3: Tempkin Isotherm Parameters for The Biosorption Of Methylene Blue Dye Onto Vigna Trilobata Pod

\begin{tabular}{c|c|c|c|c}
\hline $\begin{array}{c}\text { Temperature } \\
(\mathrm{K})\end{array}$ & $\mathrm{A}_{\mathrm{T}}(\mathrm{L} / \mathrm{mg})$ & $\mathrm{b}_{\mathrm{T}}$ & $\begin{array}{c}\mathrm{B} \\
(\mathrm{J} / \mathrm{mol})\end{array}$ & $\mathrm{R}^{2}$ \\
\hline 293 & 0.8599 & 183.158 & 13.30 & 0.983 \\
\hline 303 & 0.7351 & 196.34 & 12.83 & 0.986 \\
\hline 313 & 0.5769 & 209.018 & 12.45 & 0.983 \\
\hline 323 & 0.5532 & 226.6 & 11.85 & 0.982 \\
\hline
\end{tabular}

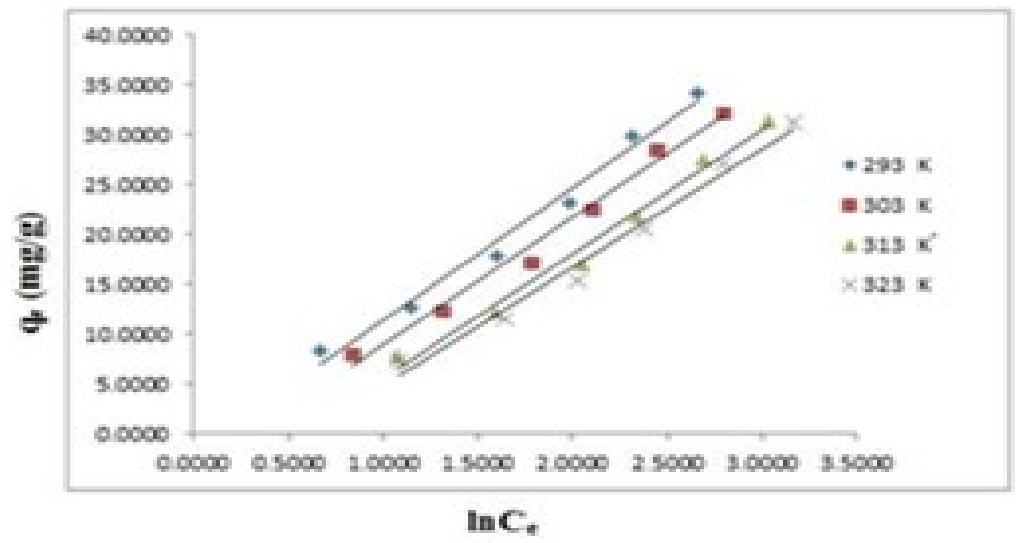

Fig.-3: Tempkin Isotherm for Biosorption of Methylene Blue Dye onto Vigna Trilobata pod

Data was further applied to the Dubinin-Radushkevich isotherm model to describe the adsorption on both homogeneous and heterogeneous surfaces and to know whether the adsorption taking place by physiosorption or chemisorption processes. The graph was plotted between $\varepsilon^{2}$ and $\operatorname{lnq}_{\mathrm{e}}$ and DR isotherm parameters were calculated.

The obtained mean free energy of adsorption (E) was $1.4204 \mathrm{KJ} / \mathrm{mol}$, which is less than $8 \mathrm{KJ} / \mathrm{mol}$ indicates the physiosorption process (Table-4). 
RASĀYAN J. Chem.

Vol. 12 | No. 4 |2176 - 2182| October - December | 2019

Table-4: DR Isotherm Parameters for Biosorption of Methylene Blue Dye on to Vigna Trilobata Pod

\begin{tabular}{c|c|c|c|c}
\hline $\begin{array}{c}\text { Temperature } \\
(\mathrm{K})\end{array}$ & $\mathrm{q}_{\mathrm{s}}(\mathrm{mg} / \mathrm{g})$ & $\begin{array}{c}\beta \\
\left(\mathrm{mol}^{2} / \mathrm{kJ}^{2}\right)\end{array}$ & $\begin{array}{c}\mathrm{E} \\
(\mathrm{kJ} / \mathrm{mol})\end{array}$ & $\mathrm{R}^{2}$ \\
\hline 293 & 28.303 & $1 \mathrm{e}-06$ & 1.4204 & 0.882 \\
\hline 303 & 27.142 & $1 \mathrm{e}-06$ & 1.4204 & 0.888 \\
\hline 313 & 25.914 & $2 \mathrm{e}-06$ & 1.0043 & 0.869 \\
\hline 323 & 24.547 & $2 \mathrm{e}-06$ & 1.0043 & 0.842 \\
\hline
\end{tabular}

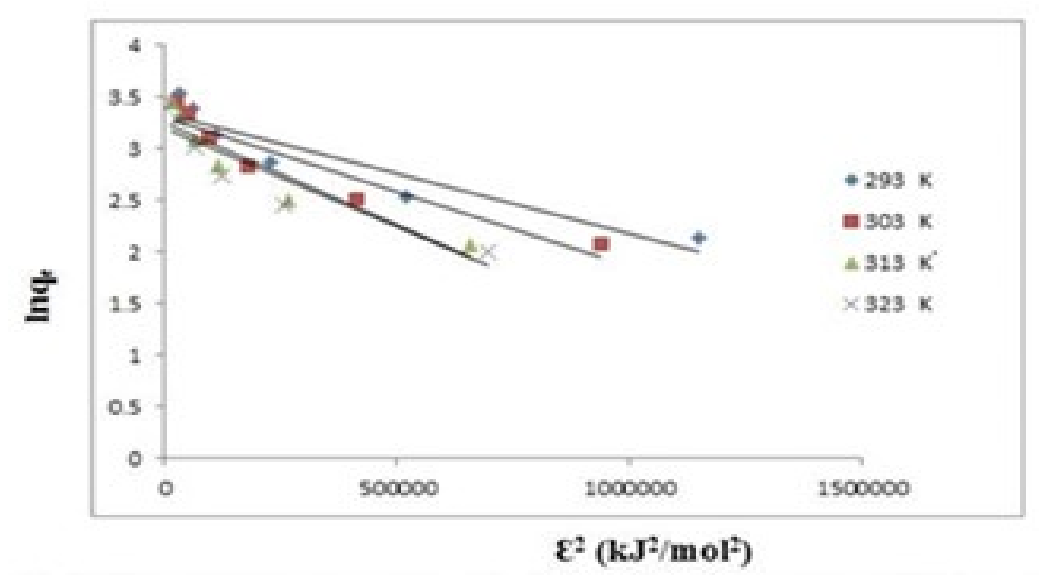

Fig.-4: DR Isotherm for Biosorption of Methylene Blue Dye onto Vigna Trilobata pod

\section{CONCLUSION}

The adsorption of Methylene blue on Vigna Trilobata pod was studied by using four different types of adsorption isotherms like Langmuir isotherm, Freundlich isotherm, Tempkin isotherm and DubininRadushkevich (DR) isotherms. Among them Freundlich adsorption isotherm is having the highest regression coefficient value and showed a better fit to the adsorption data than Langmuir, Tempkin and Dubinin-Radushkevich (DR) isotherm models in the investigation of the adsorptive removal of Methylene blue dye from wastewater using Vigna Trilobata pod. The results revealed that due to multisite adsorption, removal of Methylene blue dye occurred. Based on the high adsorption capacity values it was concluded that Vigna Trilobata pod can be used as a naturally available low-cost adsorbent for the removal of Methylene blue dye from textile industry waste water treatment.

\section{REFERENCES}

1. Ravi Vital Kandisa, K.V. Narayana Saibaba, R. Gopinadh and K. Veerabhadram, Journal of Industrial Pollution Control, 34(2), 2054(2018).

2. Fouad El-Hosiny, Mohamed Abdeldayem Abdel Khalek, Khaled Selim and Inge Osama, Journal of Applied Research on Industrial Engineering, 4(2),133(2017), DOI: 10.22105/jarie.2017.100801.1021

3. J. Hussain, I. Hussain and M. Arif, Journal of Industrial Pollution Control, 20(1), 137 (1970).

4. N. Tüfekci, N. Sivri and I. Toroz, Turkish Journal of Fisheries and Aquatic Sciences, 7(2), 97 (2007).

5. A.H. Little, Pure and Applied Chemistry, 29(1-3), 355 (1972), DOI: 10.1351/pac197229010355

6. A. Pirkarami and M.E. Olya, Journal of Saudi Chemical Society, 21(1), S179 (2017), DOI: $10.1016 / j$ jscs.2013.12.008

7. S. Sivamani and G.B. Leena, International Journal of BioSciences and Technology, 2(4), 47 (2009).

8. M.B. Desta, Journal of Thermodynamics, (2013), DOI: 10.1155/2013/375830

9. E. Heraldy, Y. Hidayat and M. Firdaus, IOP Conference Series: Materials Science and Engineering, 107(1), 012067(2016), DOI:10.1088/1757-899X/107/1/012067

10. K. Al-Sou'od, APCBEE Procedia,1, 116 (2012), DOI: 10.1016/j.apcbee.2012.03.020 
RASĀYAN J. Chem.

Vol. 12 | No. 4 | 2176 - 2182 | October - December | 2019

11. A. O. Dada, A.P. Olalekan, A.M. Olatunya and O. Dada, IOSR Journal of Applied Chemistry, 3(1), 38 (2012).

12. K.S. Bharathi and S.T. Ramesh, Applied Water Science, 3(4), 773 (2013), DOI: 10.1007/s13201013-0117-y

13. A. Tilak, R.N. Thakur, R. Sharma, M. Verma and A.K Gupta, International Journal of Pharmaceutical and Biological Science Archive, 4(4), (2016).

14. E. Osagie and C.N. Owabor, Advances in Chemical Engineering and Science, 5(03), 352 (2015), DOI: $10.4236 /$ aces.2015.53037

15. N. Ayawei, A.N. Ebelegi and D. Wankasi, Journal of Chemistry, (2017), DOI: $10.1155 / 2017 / 3039817$

16. S. Yusan and S. Erenturk, World Journal of Nuclear Science and Technology, 1(01), 6 (2011), DOI:10.4236/wjnst.2011.11002

17. N.D. Hutson and R.T. Yang, Adsorption, 3(3),189 (1997), DOI: 10.1007/BF01650130

18. K. Vijayaraghavan, T.V. Padmesh, K. Palanivelu and M. Velan, Journal of Hazardous Materials,133(1-3), 304 (2006), DOI: 10.1016/j.jhazmat.2005.10.016

19. C. Theivarasu and S. Mylsamy, Journal of Chemistry, 8(S1), S363 (2011).

20. A.A. Inyinbor, F.A. Adekola and G.A. Olatunji, Water Resources and Industry, 15, 14 (2016), DOI: 10.1016/j.wri.2016.06.001

21. F. Batool, J. Akbar, S. Iqbal, S.Noreen and S.N. Bukhari, Bioinorganic Chemistry and Applications, (2018), DOI: 10.1155/2018/3463724

22. S. Rani, M. Bansal, K. Kaur and S. Sharma, Rasayan Journal of Chemistry, 12(3), 1315 (2019), DOI: $10.31788 /$ RJC.2019.1235279

23. Samiksha Tamrakar, Rashmi Verma, Santosh Kumar Sar and Chanda Verma, Rasayan Journal of Chemistry, 12(2), 455 (2019), DOI:10.31788/RJC.2019.1225106

24. M. LutfiFirdaus, EfaSusanti, Ghufira, WiwitAlwi and EkoSwistoro, Rasayan Journal of Chemistry, 11(4), 1532 (2018), DOI:10.31788/RJC.2018.1144030

25. M. Santhi, P. E. Kumar and M. Sathy, Rasayan Journal of Chemistry, 11(4), 1423 (2018), DOI:10.31788/RJC.2018.1143066

26. H. Revathi, A. Kaviyarasu, T. Murugan, M. Dinesh Kumar and R. Sharmila Devi, Rasayan Journal of Chemistry, 11(4), 1415 (2018), DOI:10.31788/RJC.2018.1143054

27. H. Joga Rao, P. King and Y. Prasanna Kumar, Rasayan Journal of Chemistry, 11(3), 1376 (2018), DOI:10.31788/RJC.2018.1134035

[RJC-5478/2019] 